Original Article

\title{
Changes in rounded shoulder posture and forward head posture according to exercise methods
}

\author{
Do Youn Lee, MS, $\mathrm{PT}^{1)}$, Chan Woo Nam, PhD, $\mathrm{PT}^{1)}$, Youn Bum Sung, MS, $\mathrm{PT}^{1)}$, \\ Kyoung Kim, PhD, $\mathrm{PT}^{1)}$, Hae Yong Lee, PhD, $\left.\mathrm{PT}^{2}\right)^{*}$ \\ 1) Department of Physical Therapy, College of Rehabilitation Science, Daegu University, Republic of \\ Korea \\ 2) Department of Physical Therapy, Youngsan University: 288 Joonam-ro, Yangsan, Gyeongsangnam-do, \\ Republic of Korea
}

\begin{abstract}
Purpose] This study aimed to determine the effect of forward head posture-improving exercises on rounded shoulder posture when employing the self-stretch exercise, the McKenzie exercise, and the Kendall exercise as intervention methods based on previous studies that reported negative effects of unbalanced posture and musculoskeletal problems on forward head posture and rounded shoulder posture. [Subjects and Methods] The selected 28 subjects were randomly assigned into the McKenzie exercise group $(n=9)$, the self-stretch exercise group $(\mathrm{n}=10)$, and the Kendall exercise group $(\mathrm{n}=9)$. To compare the forward head posture, the craniovertebral angle was used. To measure the rounded shoulder posture, the scapular index was used. [Results] There were significant differences in the craniovertebral angle and scapular index within the groups and no significant differences between the groups. [Conclusion] The result of this study showed that all interventions increased the craniovertebral angle and the scapular index, which revealed that the applied exercises had a positive effect on forward head posture and rounded shoulder posture.

Key words: Forward head posture, Rounded shoulder, Exercise
\end{abstract}

(This article was submitted Apr. 23, 2017, and was accepted Jul. 18, 2017)

\section{INTRODUCTION}

Muscular and skeletal structures can change into an incorrect shape due to a reduction in physical activity and inappropriate posture habits in daily living ${ }^{1)}$. Forward head posture (FHP) is defined as excessive anterior positioning of the head in relation to a vertical reference line ${ }^{2}$. Rounded shoulder posture (RSP) refers to a posture characterized by acromion protraction in front of the line of gravity, shoulder protraction, and downward rotation as well as anterior tilt ${ }^{3}$. Also, long-term use of smart phones leads to wrong posture such as forward neck posture, rounded shoulders and slouched posture ${ }^{4}$. Changes in physical functions that occur due to rounded shoulders can cause one or more abnormal conditions in a complex structure consisting of the head, neck, and shoulders ${ }^{5}$. FHP and RSP deform the normal relationship of the muscles and the bone structures, which are correlated ${ }^{6}$. To improve FHP, many physical therapy methods can be used. The McKenzie exercise is a self-therapy exercise done by patients through repetitive motions and includes mobilization, manipulation. Its main focus is on stretch exercises $^{5)}$, it is known to be effective in neck posture correction ${ }^{7}$. The Kendall exercise strengthens deep cervical flexor and shoulder retraction muscles and stretches pectoral muscles, thereby correcting unstable FHP and helping to correct the alignment of the neck ${ }^{8}$. Self-stretch exercise consists of Mckenzie's neck exercise for reduced pain and Kendall's strengthens exercise. Although many studies reported that the McKenzie and the Kendall exercise both reduced neck pain, few studies have been conducted on the effect of their exercises on RSP. Therefore, this study aimed to determine the effect of

*Corresponding author. Hae Yong Lee (E-mail: cyberlhy@nate.com)

(C2017 The Society of Physical Therapy Science. Published by IPEC Inc.

(c) (1) $\odot$ This is an open-access article distributed under the terms of the Creative Commons Attribution Non-Commercial No Deriva-

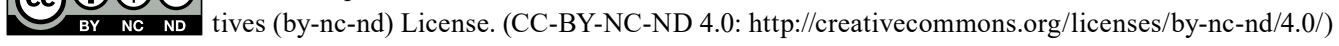


FHP-improving exercises on RSP when employing the McKenzie exercise, the self-stretch exercise and the Kendall exercise as intervention methods.

\section{SUBJECTS AND METHODS}

This study chose 28 subjects who were 19 years old or older in Daegu city. The selected 28 subjects were randomly assigned into the McKenzie exercise group ( $n=9, M E G)$, the self-stretch exercise group ( $n=10$, SSEG), and the Kendall exercise group ( $n=9, K E G)$. The selection criteria were: 53 degrees or lower according to craniovertebral angle (CVA); those who had not any regular exercise for the last 6 months; and those who used a smartphone or computer for 4 hours or more per day on average. Informed consent was voluntarily obtained from all the subjects prior to participation in the study, and this study was approved by the Institutional Review Board of Daegu University.

8-week intervention was applied after a pre-test and a post-test was conducted. To compare the forward head posture, CVA was used. To measure the RSP, the scapular index was used. Sufficient explanation was given to the subjects to follow the correct method. The exercise manual and the exercise logbook were distributed to the subjects to follow the correct exercise program and to record the exercises once they were done. The subjects were contacted periodically to check whether they had conducted the exercises.

McKenzie exercises consist of 7 exercise motions performed for $7 \mathrm{sec}$ at static maximum muscle strength and $3 \mathrm{sec}$ rest prior to procceding to the next exercise motion. This exercies repeated 20 times ${ }^{7,9)}$. The self-stretch exercise methods were as follows: (1) Place both hands on the shoulders and push out the chest; and (2) Place one hand over the shoulder and grasp the elbow of the turned hand, with the other hand over the head and slowly pull it inward until it has reached the full stretched point; and (3) Throw back the head, and turn it until it has reached the fully stretched point; and (4) Look straight ahead and slowly turn the head horizontally and stop when the maximum value is reached; and (5) Throw back the head, and turn it until it has reached the fully stretched point; and (6) Lower the head, and turn it until it has reached the maximal point ${ }^{10)}$. Each motion had to be maintained for $10 \mathrm{sec}$ followed by $5 \mathrm{sec}$ rest. Each subjects performed $10 \mathrm{sets}$. The Kendall exercise methods were as follows: (1) stretching pectoralis muscle, placing both hands on theoccipital area and pulling the elbows back up and performing arm abduction and external rotation; and (2) strengthening shoulder retraction, putting a TheraBand around a secure object and pulling the band back with both hands as far as possible to move the shoulder blades toward each other in a standing position; and (3) Strengthening the deep cervical flexors, lying flat on the back with the chin down and then lifting the head; and (4) Stretching the cervical extensors, placing both hands on the occipital area in a sitting position followed by a flexed neck posture with the head down to stretch the cervical extensors. This exercise was repeated 15 times ${ }^{8,11,12)}$. All exercises consist of total $25 \mathrm{~min}$ a day and performed three times a week for 8 weeks.

CVA was assessed using a digital, lateral-view photograph of the subjects in their usual standing posture. Markers were attached to the seventh cervical (C7) vertebra, and to the tragus in the ear and the acromion of each subject's shoulders, and a digital camera was installed 33 inches away from the ground and 104 inches away from the subject. Each subject had their eyes to gaze at their eyes reflected at the front mirror then flexed and extended their head three times in the standing position as much as they could. A picture was then taken when they stopped at their most comfortable posture ${ }^{9,10)}$. A photograph was taken laterally using a digital camera (AlpaNEX-6; Sonny, China). The CVA was calculated using Adobe Photoshop program CS6. To assess rounded shoulders, subjects were asked to stand normally with hands hanging beside the body. At their standing position, the coracoid process (CP), the sternal notch (SN), the posterolateral angle of acromion (PLA), and the adjacent thoracic vertebral spine (TS) were found and marked. Distance between the coracoid process and sternal notch, and that between the posterior edge of acromion process and adjacent thoracic vertebral spine was measured with tape and scapular index was estimated according to the following formula. The scapular index is CP to SN / PLA to TS $\times 100^{13)}$.

The analysis of the study results was done using the statistical processing program SPSS 20.0 for Windows, and means and standard deviations of all results were calculated. In order to determine the pre-post change within the groups a paired t-test was used, and to determine the difference in changes between groups ANOVA was used. The post-test was done by using LSD and its level of significance $(\alpha)$ was set at 0.05 .

\section{RESULTS}

The observational data regarding CVA and scapular index results within the groups is summarized in Table 1. Changes in the CVA and the scapular index results between the groups before and after the intervention had no significant differences statistically $(p>0.05)$. The post-test results using the LSD did have a significant difference between SSEG and KEG statistically $(\mathrm{p}<0.05)$.

\section{DISCUSSION}

The CVA results that measured a degree of FHP showed that all three groups had a statistically significant difference and, there was no significant improvement in changes in the CVA between groups. This result implies that each of the three exercises had a similar effect on FHP improvement. This study result is consistent with that of Kim ${ }^{14)}$, in which the CVA was 
Table 1. Craniovertebral angle (CVA), round shoulder of the three groups

\begin{tabular}{lllll}
\hline & & \multicolumn{1}{c}{ MEG $(\mathrm{n}=9)$} & SSEG $(\mathrm{n}=10)$ & \multicolumn{1}{c}{ KEG $(\mathrm{n}=9)$} \\
\hline \multirow{2}{*}{ Forward head posture } & $\left.\mathrm{CVA}^{\circ}{ }^{\circ}\right)-$ pre & $50.00( \pm 2.74)$ & $47.60( \pm 2.01)$ & $50.00( \pm 2.35)$ \\
& ${\operatorname{CVA~}\left({ }^{\circ}\right)-\text { post }}_{*}^{*}$ Round shoulder & $54.89( \pm 4.78)^{* *}$ & $50.80( \pm 3.08)^{* *}$ & $53.33( \pm 3.57)^{*}$ \\
& Scapular Index - pre & $66.16( \pm 5.28)$ & $67.22( \pm 3.34)$ & $66.26( \pm 7.93)$ \\
& Scapular Index - post & $74.61( \pm 4.45)^{* *}$ & $76.20( \pm 3.81)^{* *}$ & $80.83( \pm 4.05)^{* *}$ \\
\hline
\end{tabular}

Values are expressed as mean ( \pm standard deviation)

FHP is represented by carniovervebral angle (CVA), greater CVA values indicates less FHP

$* \mathrm{p}<0.05, * * \mathrm{p}<0.01$ within each groups

much improved via the McKenzie exercise over a period of 4 weeks. Furthermore, a study by Park ${ }^{15)}$, in which strengthening exercises of the neck and chest muscles using elongation and elastic bands was applied and reported a positive effect of the exercise on the CVA and the RSP. Moreover, another study proved that the Kendall exercise had a positive effect on the CVA through changes in the CVA by comparing treatment and control groups where 10-week Kendall exercises with five steps were applied for 2 weeks ${ }^{16}$. Also the other study showed a positive effect of horse-riding exercise and Kendall exercise groups on FHP after an 8-week intervention ${ }^{11)}$. Because the SSEG had no less effect statistically than the other exercise groups, it can be suggested as another exercise to improve FHP.

The scapular index results that all three groups had a statistically significant difference and between the groups before and after the intervention had no significant difference statistically. The post-test results using the LSD did have a significant difference between SSEG and KEG statistically. This result seemed that KEG is more focus on shoulder retractors than SSEG. Mckenzie and Kendall exercises are commonly used for improvement FHP. Also, self-stretch exercise can suggest new exercise for improvement FHP and RSP because SSEG have similar effect other groups. A study reported that a positive effect on FHP and RSP by applying the intervention of chest muscle stretch and scapular protraction exercises using a foam roller as a chin-in and chest exercise for swimming athletes ${ }^{17}$. Also, the other study showed that correct alignment and stability improvements of head, shoulder, and upper extremities as well as muscle strengthening by applying the stretch exercise of chest muscles and shoulder retraction muscles for 6 weeks ${ }^{18}$. Also, a study reported positive results on the CVA and the RSP measurements through 2-week chest muscle exercises and expected that the applied stretching intervention would play a major role in treating FHP and RSP in the clinical field ${ }^{19}$. Compared to the previous studies, our study also increased the CVA and the scapular index, which revealed that the applied exercises had a positive effect on FHP and RSP. Also, it is recommended to be included in a large sample size in a future study.

\section{REFERENCES}

1) Lee CY: Postural patterns of daily life of male high school students by positional distortion. Unpublished master's thesis, Korea National University of Education, Cheongwon-Gun, 2004.

2) Szeto GP, Straker L, Raine S: A field comparison of neck and shoulder postures in symptomatic and asymptomatic office workers. Appl Ergon, 2002, 33: 75-84. [Medline] [CrossRef]

3) Yang H, Bae S: Effects of shortening of pectoralis minor muscle on muscle activity of trapezius and pectoralis major muscles. Journal of The Korean Society of Integrative Medicine, 2013, 1.4: 85-92. [CrossRef]

4) Janwantanakul P, Sitthipornvorakul E, Paksaichol A: Risk factors for the onset of nonspecific low back pain in office workers: a systematic review of prospective cohort studies. J Manipulative Physiol Ther, 2012, 35: 568-577. [Medline] [CrossRef]

5) Mckenzie R: Treat your own neck. Spinal Publications, 1997.

6) Raine S, Twomey LT: Head and shoulder posture variations in 160 asymptomatic women and men. Arch Phys Med Rehabil, 1997, 78: 1215-1223. [Medline] [CrossRef]

7) Mckenzie R: The cervical and thoracic spine: mechanical diagnosis and therapy. Ortho Physic Ther, 1990.

8) Kendall, Florence P, Henry O: Muscles: testing and function with posture and pain. 2005.

9) Youn JH, Sung DJ: The influence of Mckenzie approach on head, shoulder posture of the patients with chronic neck pain. The Research Institute of Physical Education \& Sports Sci, 1998, 17: 79-90.

10) Lee MH, Song JM, Kim JS: The effect of neck exercises on neck and shoulder posture and pain in high school students. J Korean Soc Phys Ther, 2011, 23: $29-35$.

11) Kim KH, Kim SG, Hwangbo G: The effects of horse-riding simulator exercise and Kendall exercise on the forward head posture. J Phys Ther Sci, 2015, 27: 1125-1127. [Medline] [CrossRef]

12) Harman K, Hubley K, Cheryl L: Effectiveness of an exercise program to improve forward head posture in normal adults: a randomized, controlled 10-week trial. J Manual Manip Ther, 2005, 13: 163-176. [CrossRef]

13) Korooshfard N, Ramezanzadei H: Relationship of self esteem with forward head posture and round shoulder. Procedia Soc Behav Sci, 2011, 15: 3698-3702. [CrossRef] 
14) Kim SY, Kim NS, Kim LJ: Effects of cervical sustained natural apophyseal glide on forward head posture and respiratory function. J Phys Ther Sci, 2015, 27: 1851-1854. [Medline] [CrossRef]

15) Park HC, Kim YS, Seok SH, et al.: The effect of complex training on the children with all of the deformities including forward head, rounded shoulder posture, and lumbar lordosis. J Exerc Rehabil, 2014, 10: 172-175. [Medline] [CrossRef]

16) Diab AA, Moustafa IM: The efficacy of forward head correction on nerve root function and pain in cervical spondylotic radiculopathy: a randomized trial. Clin Rehabil, 2012, 26: 351-361. [Medline] [CrossRef]

17) Lynch SS, Thigpen CA, Mihalik JP, et al.: The effects of an exercise intervention on forward head and rounded shoulder postures in elite swimmers. Br J Sports Med, 2010, 44: 376-381. [Medline] [CrossRef]

18) Wang CH, McClure P, Pratt NE, et al.: Stretching and strengthening exercises: their effect on three-dimensional scapular kinematics. Arch Phys Med Rehabil, 1999, 80: 923-929. [Medline] [CrossRef]

19) DiVeta J, Walker ML, Skibinski B: Relationship between performance of selected scapular muscles and scapular abduction in standing subjects. Phys Ther, 1990, 70: 470-476, discussion 476-479. [Medline] [CrossRef] 